\title{
NOTE ON GENUS HYOIDEA PUTON (HEMIPTERA).
}

\author{
By E. P. Van Duzee, \\ Berkeley, California.
}

Mr. Otto Heidemann has very kindly sent to me for examination a cotype of Hyoidea horvathi Montd. and a careful examination of this confirms my assignment of this genus and Bolteria Uhler in my synoptical tables of the Miridæ recently published by the University of California and in the Check List of the Hemiptera, in both of which I drop Hyoidea as wanting in our fauna and arrange Bolteria in the Phylini near Plagiognathus. Dr. Reuter did not know Bolteria amicta, the type of the genus, but placed picta in Hyoidea and described a new species grisea. An examination of fresh material of picta shows that it wants the free converging arolia found in Hyoidea and must be placed in Subfamily Phylinæ. It is probably safe to assume that amicta is congeneric with picta although the type is lost and so far as I know the species is now unrecognized.

I am also indebted to Mr. Heidemann for the opportunity of examining typical examples of Hyoidea grisea Reuter, and, as Mr. Heidemann suggests in his letter to me, this proves to be a synonym of Labopidea chloriza Uhler. I am, however, convinced that both chloriza and grisea are identical with the earlier described Tinicephalus simplex Uhler and that we must use the generic name Labopidea for the species. Hyoidea differs from Labopidea in having a more polished surface with punctured pronotum, a longer and more parallel form with the pronotum but little wider behind, and a sharp and carinate hind margin to the vertex. The aspect of Hyoidea is quite different from Labopidea and I believe it should be considered distinct. Both of these genera have free converging arolia and belong to the Orthotylini. 

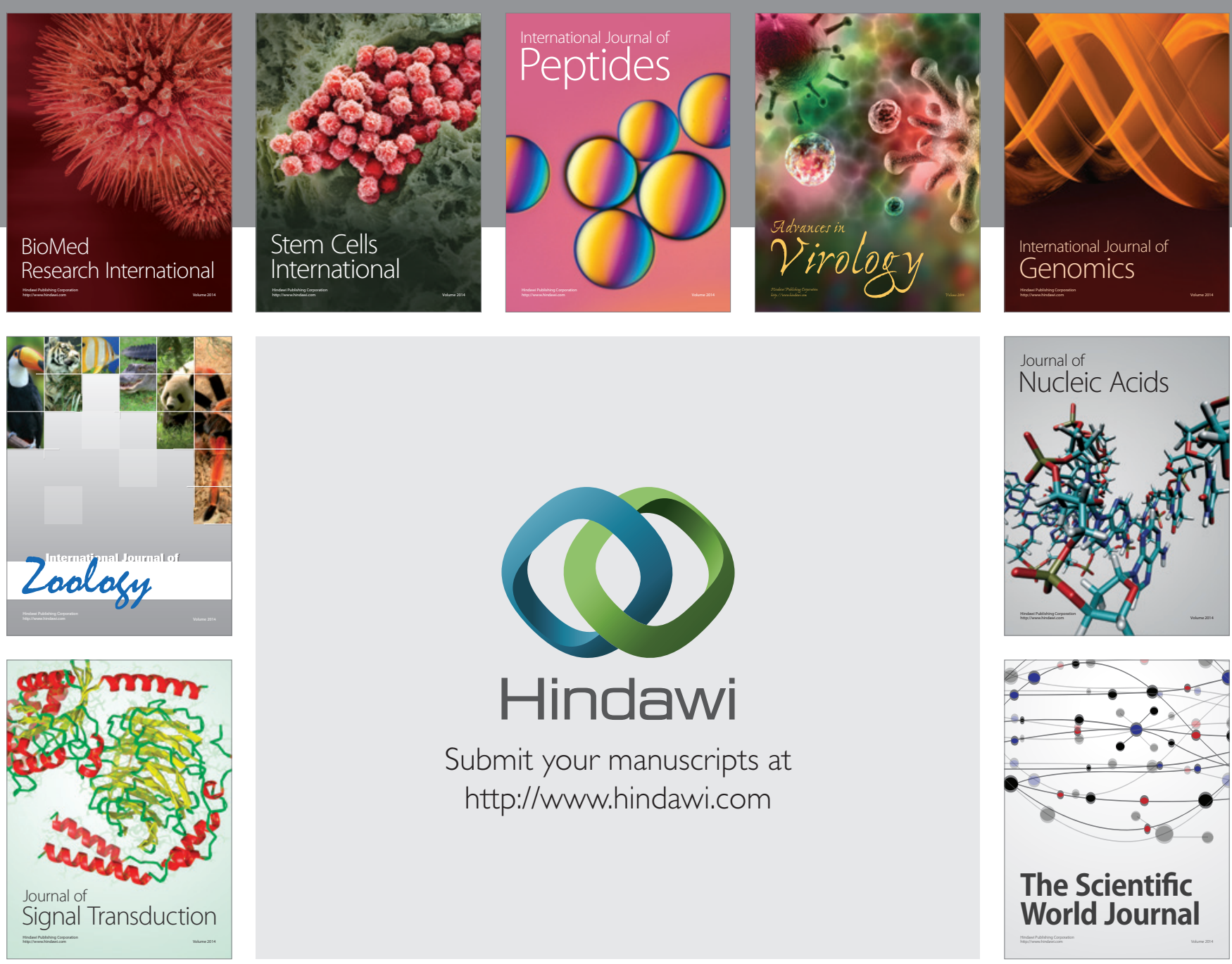

Submit your manuscripts at

http://www.hindawi.com
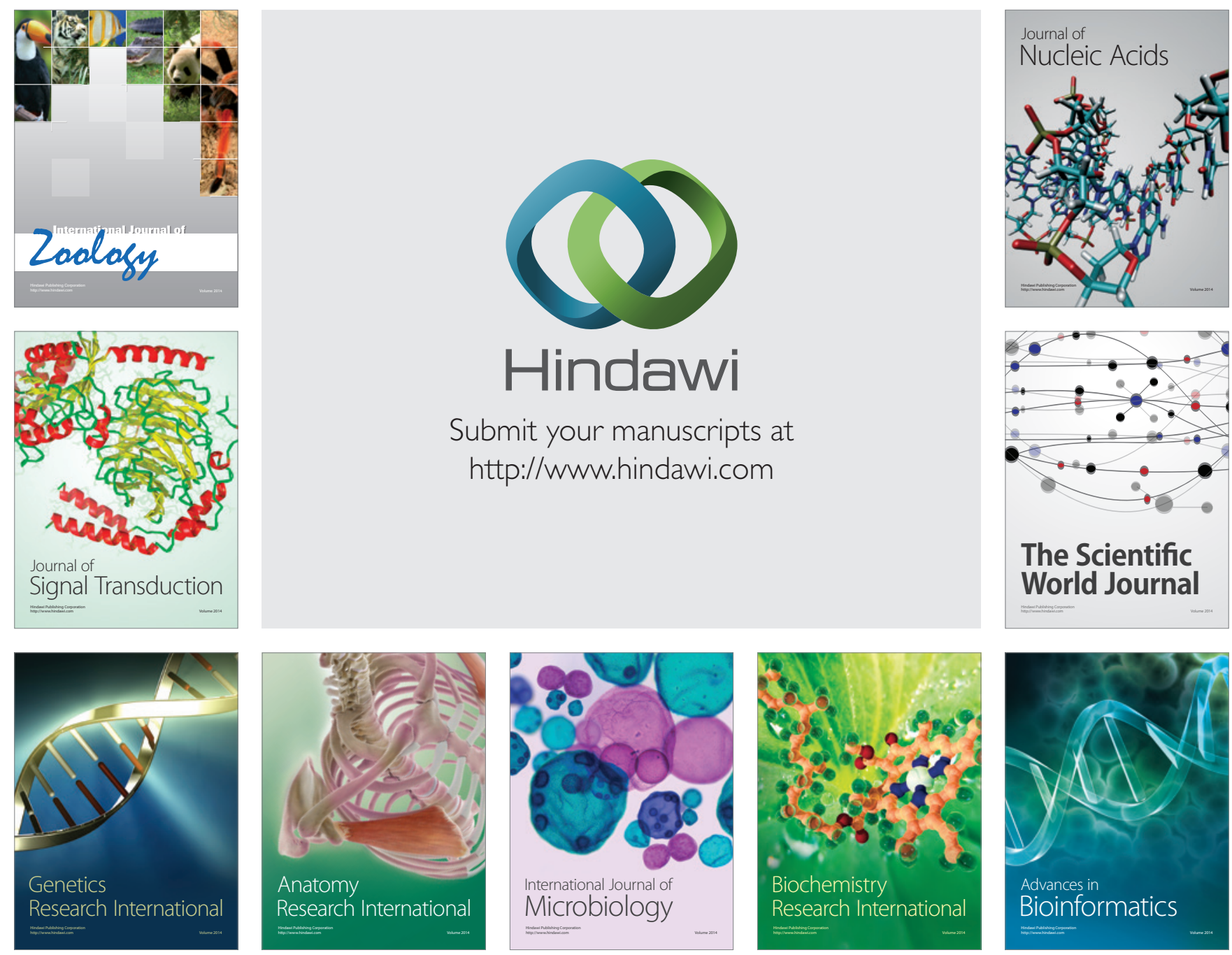

The Scientific World Journal
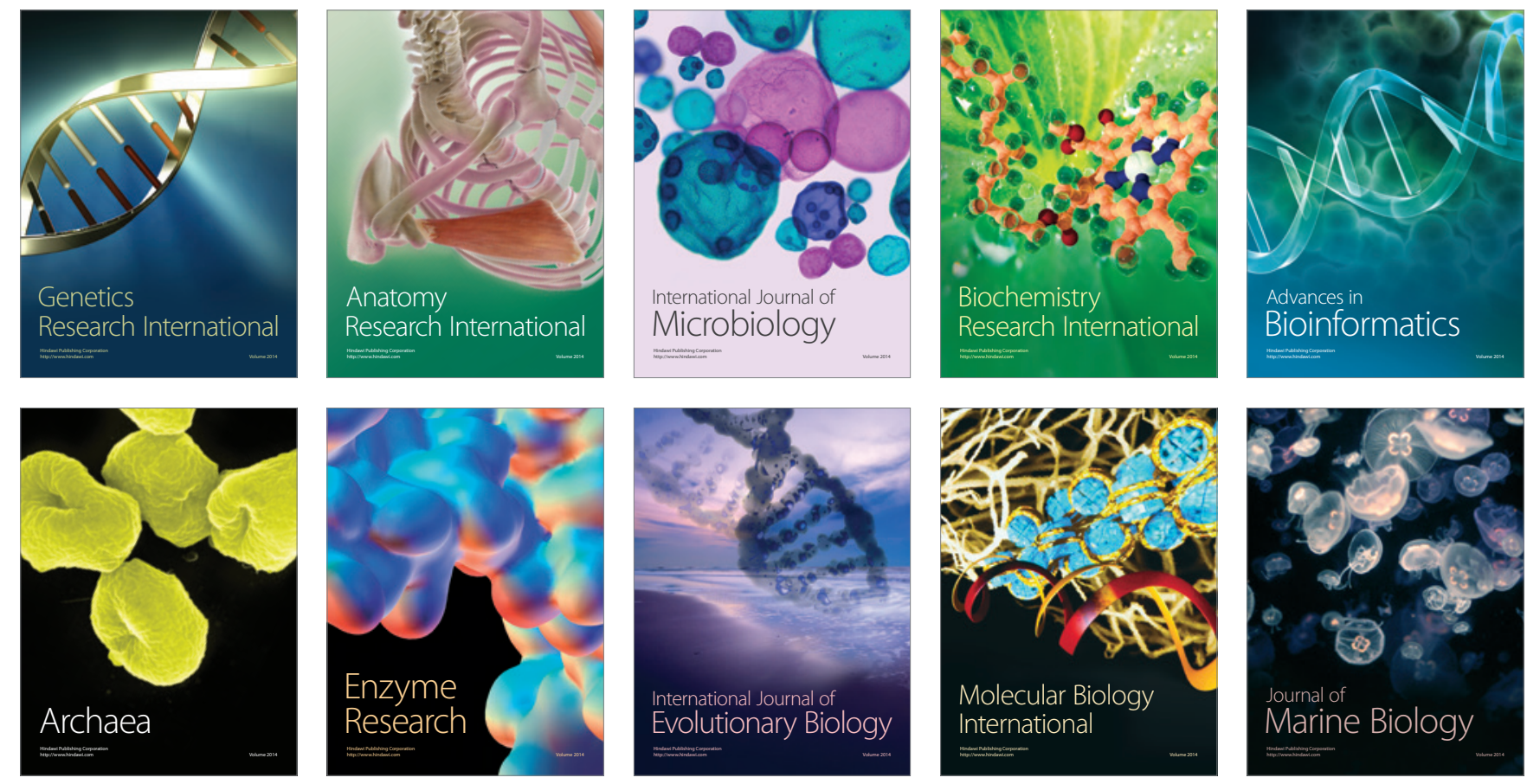